\title{
SIMULATING LAND USE/COVER CHANGES OF NENJIANG COUNTY BASED ON CA-MARKOV MODEL
}

\author{
Baoying $\mathrm{Ye}^{1}$, Zhongke Bai ${ }^{2}$ \\ ${ }^{1}$ China University of Geosciences, College of Land Science \& Techniques, No. 29 Xueyuan \\ Rd. Beijing, 100083, People's Republic of China, Email: woodfish_ye@yahoo.com.cn \\ ${ }^{2}$ China University of Geosciences, College of Land Science \& Techniques, No. 29 Xueyuan \\ Rd. Beijing, 100083, People's Republic of China, Email: baizk@cugb.edu.cn
}

Abstract: Nenjiang County experienced intense land use/cover changes during 19852000.The remote sensing and GIS methods were used to find the changes temporally and spatially. The result indicates: the forests were fallen in a large area, from $49.46 \%$ to $39.03 \%$ of total land area. Simultaneously, the croplands were increased rapidly from $26.02 \%$ to $37.42 \%$. The conversion of forests and croplands were the main activities of landuse. Oppositely, Urbanization resulted in the decrease of the croplands in Southeast China during this period. In order to predict the landuse in 2015 and 2030 in this region, the CA-Markov model was taken. The predicting result indicates: From 2000 to 2015, 2000 to 2030, the croplands would increase $2.53 \%$ and $2.85 \%$ respectively, which account that the croplands exploitation reached a peak, only a small area of land can be used in croplands.

Keywords: Nenjiang County; Remote Sensing; GIS CA-Markov

\section{INTRODUCTION}

Land use/cover change is one of important factors that resulted in global warming (Turner et al., 1994). Recently, China is susceptible to land degradation on account of its climate, its geography and considerable population pressure on the land. Land use/cover changes during the past decades have arguably been the most widespread and intense in China's history. In Southeast China, the urban extending and cultivated land 
shrinking are the main activities. Oppositely, cropland increased in the Northeast China. The Nenjiang County is the typical area that the croplands increased and the forest decreased (YE. Baoying, 2003).

The objectives of this study are (1) to analyze the temporal and spatial changes of Nenjiang county during 1985-2000; (2) to simulating and predict the land use of Nenjiang region in 2015 and 2030 based on CA-Markov model.

\section{DATA AND METHODS}

\subsection{Study area}

Nenjiang County is located in the West of Heilongjiang province, China

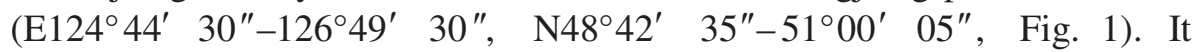
belongs to North Temperate Zone and continental monsoon climate where the annul temperature is $-0.1^{\circ} \mathrm{C}$, and annul average rainfall is $550-600 \mathrm{~mm}$. The forest is the one of main land use types, mostly covering the low hill in the north. The cropland was planted in the south, which is a part of Nenjiang alluvial plain that is the main food supplying base of China.

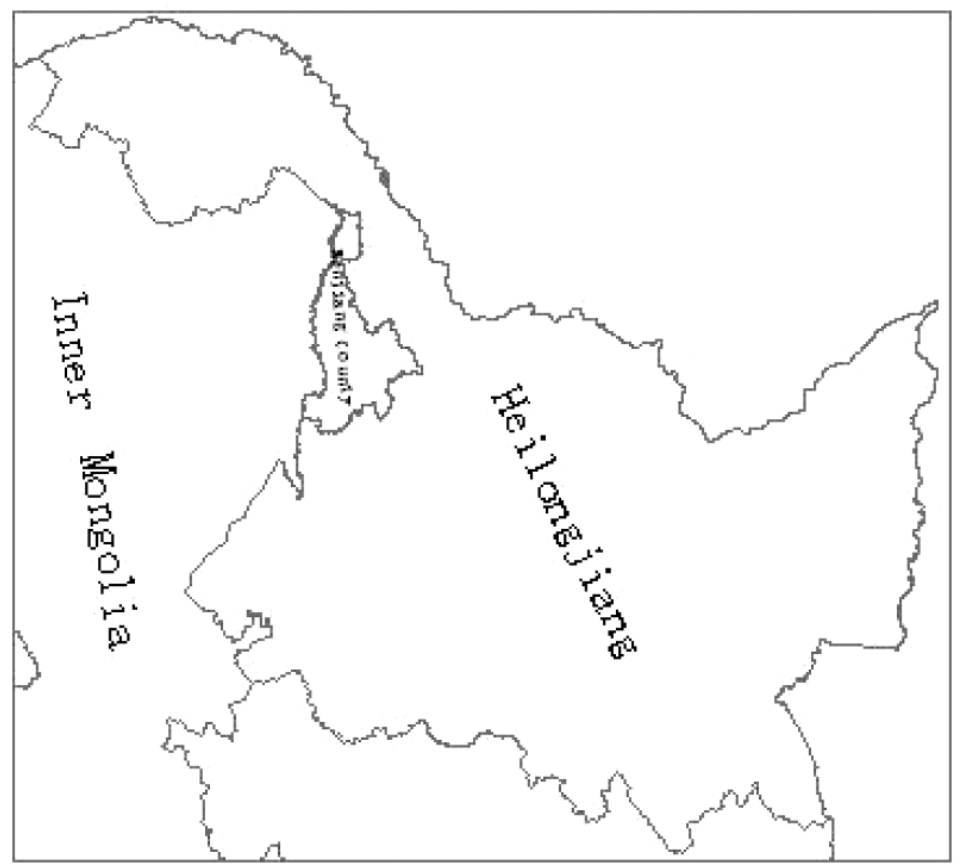

Fig. 1. The location of the study area 


\subsection{Image and process}

Four TM(1985) and $4 \mathrm{ETM}+(2000)$ scenes covering the region were used. The images were processed in the Erdas 9.1 (Leica, 2006), the process included band combination, color enhance and geometric correction, which the 20-30 GCPS were collected from the topologic map at a scale of 1:100000, and a RMS less than 1 pixel. The images were resampling to $30 \mathrm{~m}$ with the bilinear interpolation.

The artificially and interactively interpreting method was taken to extract the land use/cover classifying information. We used 6 main classes and 24 subclasses for this region. The main classes consist of cropland, forest, grassland, waters, urban/built-up land, and swamp. The ArcGIS 9.2 (ESRI, 2006) were used to interpret and extract the vector data of land use/cover from the images of 1985 and 2000.The classified precision were evaluated is $88.95 \%$ (YE Baoying, 2002).

\subsection{Markov chain}

Markov chain is a series of random values whose probabilities at a time interval depend on the value of the number at the previous time. A given parcel of land theoretically may change from one category of landuse, to any other, at any time. Markovian analysis uses matrices that represent all the multi-directional landuse changes between all the mutually exclusive landuse categories.

The Markov chain equation was constructed using the landuse distributions at the beginning (Mt) and at the end $(\mathbf{M t}+1)$ of a discrete time period as well as a transition matrix $\left(\mathbf{M}_{\mathbf{L c}}\right)$ representing the landuse changes that occurred during that period. Under the assumption that the sample is representative of the region, these proportional changes become probabilities of landuse change over the entire sample area and form the transition matrices. The three matrices created above were then assembled to form a 'link' in the Markov chain using the following equation (Michael R et al.,1994):

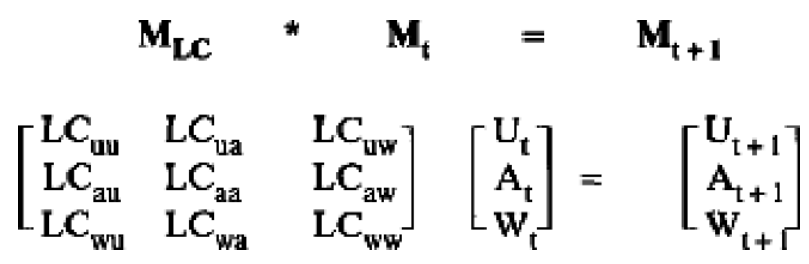

Where $\mathbf{U} \mathbf{t}$ represents the probability of any given point being classified as urban at time $t$, and $\mathrm{LC}_{\text {ua }}$ represents the probability that an agricultural point at $t$ will change into urban land by $t+1$ and so on. Iteration of this matrix equation derives the equilibrium matrix $\mathrm{Q}$ which by definition occurs when 
the multiplication of the column vector (landuse distribution) by the transition matrix yields the original column vector, i.e., $\mathbf{M}_{\mathbf{L C}} * \mathbf{M} \mathbf{t}=\mathbf{M t +}$ $1=$ Mt .

\subsection{CA model}

Cellular automata (CA) were firstly used by Von Neumann (Von Neumann J, 1966) for self-reproducible systems. CA is discrete dynamic systems in which the state of each cell at time $t+1$ is determined by the stated of its neighboring cells at time according the pre-defined transition rules. CA as a method with temporal-spatial dynamics can simulate the evolution of things in two dimensions. This method has been widely applied in many fields of geography. Especially, it was used earlier to modeling the city growing and the land use evolution (Tobler WR, 1970; Couclelis H, 1985, 1989; White R, 1993)

CA is inherently spatial and dynamic, which makes them ideal choices for the representation of spatial and dynamic processes. Because of these properties they have been widely used in land use simulations. Furthermore, they are simple and computationally efficient and therefore make it possible to model land use dynamics at high resolution.

The similarities between CA and raster GIS data structure have led to the implementation of CA models inside GIS by many researchers. CA serves as analytical engines to enable dynamic modeling within GIS. Integrated GIS and CA models for the dynamic simulation of land use changes can generate realistic simulations of land use patterns and spatial structure.

\subsection{CA-Markov model}

Markov chain and CA both are the discrete dynamic model in time and state. One inherent problem with Markov is that it provides no sense of geography. The transition probabilities may be accurate on per category basis, but there is no knowledge of the spatial distribution of occurrences within each landuse category. We will use CA to add spatial character to the model. The Idrisi 15 (Clark Labs, 2006) integrates CA with Markov very well. In this paper, we take the Idrisi GIS software to simulate the land use in this region. This model needs some parameters as follows:

(1) Landuse data of 2000 is specified as the initial image. The transition probabilities areas from the years 1985 to 2000 were used for Markov conditional probability matrix.

(2) Generate the suitability maps: according to the underlying landuse change dynamics between the years 1985 and 2000, a series of suitability maps consisting of cropland, forest, grassland, urban/built-up land were empirically derived from the land cover images, which values are 


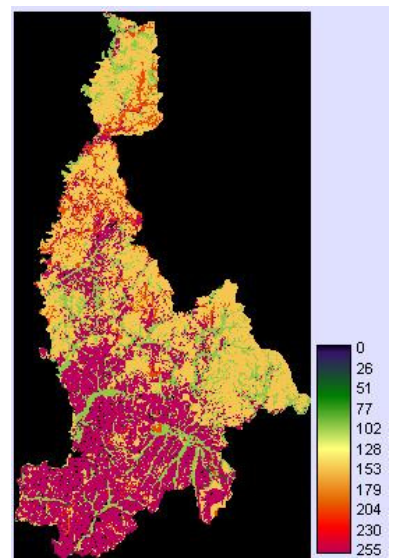

Fig. 2. The suitability map of croplands

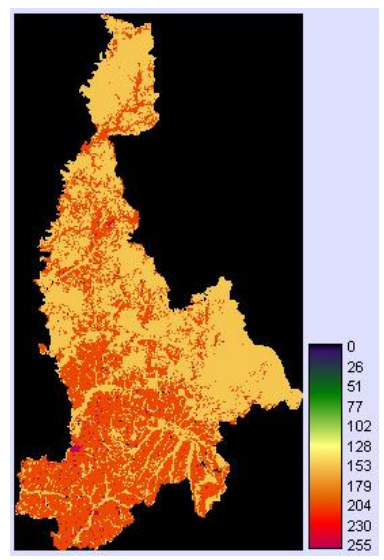

Fig. 5. The suitability map of urban/built-up land

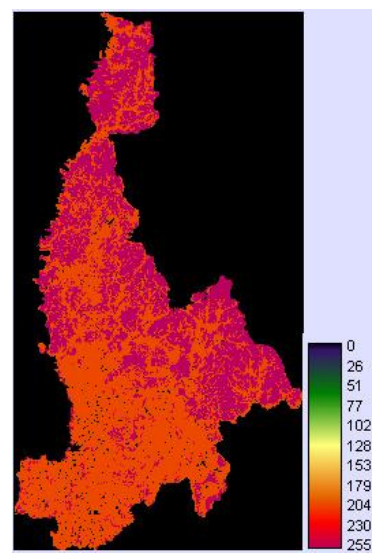

Fig. 3. The suitability map of forests

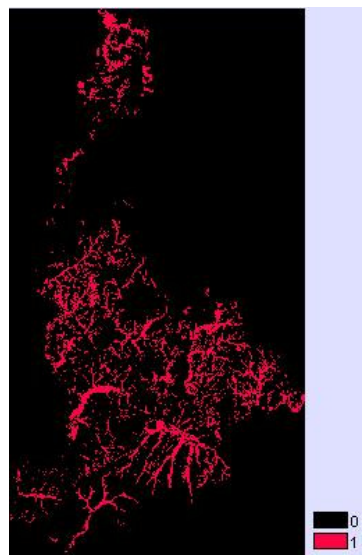

Fig. 6. The suitability map of waters

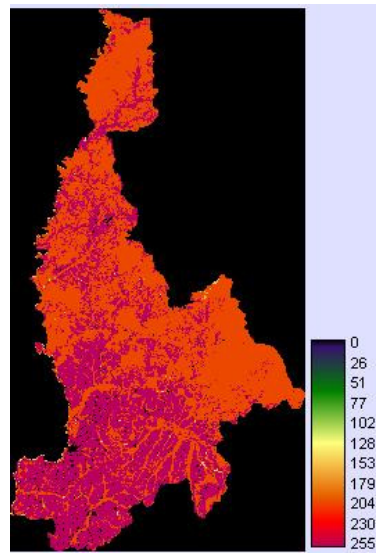

Fig. 4. The suitability map of grasslands

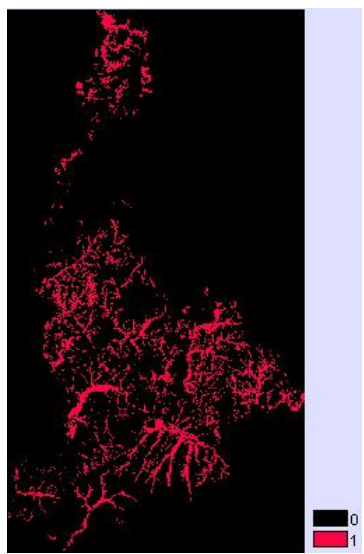

Fig. 7. The suitability map of swamps

standardized between 0 and 255 (Figs. 2-5). The waters, swamp are conditional constraints, which is a bool value (Figs. 6-7).

(3) A CA filter is used to generate a spatial explicit contiguity-weighting factor to change the state of cells based on its neighbors. The filter is a $5 \times 5$ contiguity filter as follows:

\begin{tabular}{|l|l|l|l|l|}
\hline 0 & 0 & 1 & 0 & 0 \\
\hline 0 & 1 & 1 & 1 & 0 \\
\hline 1 & 1 & 1 & 1 & 1 \\
\hline 0 & 1 & 1 & 1 & 0 \\
\hline 0 & 0 & 1 & 0 & 0 \\
\hline
\end{tabular}

(4) CA loops times: over a 15-year period to 2000 is used to predict the landuse in the 2015, and a 30-year period to 2030 . 


\section{RESULT AND ANALYSIS}

\subsection{Changes from 1985 to 2000}

This region is the ecotone of cultivation and forests production. The forest covers on the low hill in the north of county. The cultivated land distributes in the plain of south, which is the part of Nenjiang River alluvial plain. From the land use/cover maps of the year 1985 (Fig. 8), the forest is the main land use type, covering the 48 percent of the total areas. The second main land use type is the cropland, which occupied 26.12 percent. Subsequently, the swamp occupied 17.53 percent, which distributes near the sides of river. Other landuses are less than 10 percent.

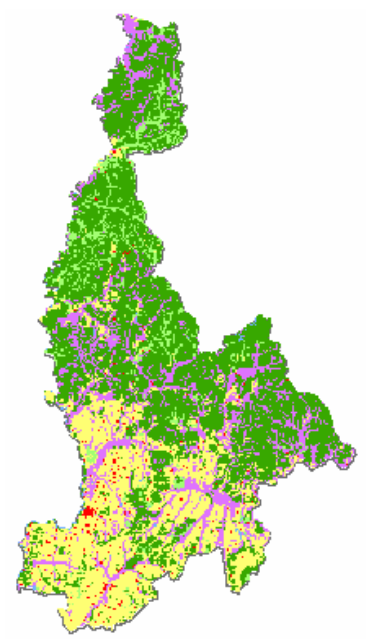

Fig. 8. The classified land use/cover map of Nenjiang County in 1985
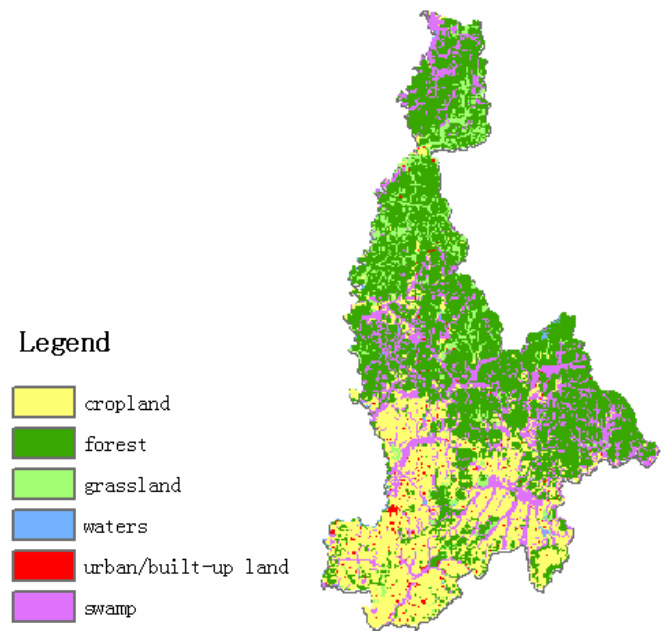

Fig. 9. The classified land use/cover map of Nenjiang County in 2000

From the year 1985 to 2000 , the cropland increased rapidly from 26.12 percent to 37.42 percent (Table 1, Figs. 8-9). The forested lands have however, decreased substantially from 48.46 percent in 1985 to 39.03 percent in 2000, a record loss of 9.43 percent. Other landuses changed slightly, which grassland decreased 2.22 percent, waters increased 0.6 percent, urban and built-up land increased 0.04 percent and the swamps decreased 0.73 percent. An analysis of the changes in table and figure shows: The forested lands have given way mainly to the expanding agriculture. The forests were felled took place on the foot of hill near the sides of river. An area of $147,231 \mathrm{hm}^{2}$ forests were converted into croplands during the year 1985 and 2000. Only $1,661 \mathrm{hm}^{2}$ were converted into grasslands, and $609 \mathrm{hm}^{2}$ replaced by the 
swamps. Besides of forests, the grasslands and swamps were also partly converted into croplands, which the converting areas are $19,693 \mathrm{hm}^{2}$ and $13,955 \mathrm{hm}^{2}$ respectively.

Table 1. Major land use/cover conversions from 1985 to 2000 (unit:hm²)

\begin{tabular}{|l|c|c|c|c|c|c|}
\hline 1985 & Cropland & Forest & Grassland & Waters & Urban/built-up & Swamp \\
\hline Cropland & 0 & 1263 & 298 & 0 & 170 & 1666 \\
\hline Forest & 147231 & 0 & 1661 & 0 & 405 & 609 \\
\hline Grassland & 19693 & 686 & 0 & 194 & 28 & 679 \\
\hline Waters & 0 & 0 & 0 & 0 & 0 & 0 \\
\hline Urban/built-up & 0 & 0 & 0 & 0 & 0 & 0 \\
\hline Swamp & 13955 & 0 & 37 & 661 & 19 & 0 \\
\hline
\end{tabular}

\subsection{Land use/cover simulation}

Making use of the CA-Markov model, the land uses in the year 2015 and in 2030 were predicted. From Figs. 10-12, the cropland increased from 37.42 percent in 2000 to 39.95 percent in 2015, an increment of 2.43 percent. In 2015. The forested lands decreased to 36.51 percent in 2015, a loss of 2.52 percent. In the year of 2030, the cropland would account for 40.27 percent and the forested 36.48 percent. From this trend, the cropland increased is limited since 2000. No more land is suitable to cropland.

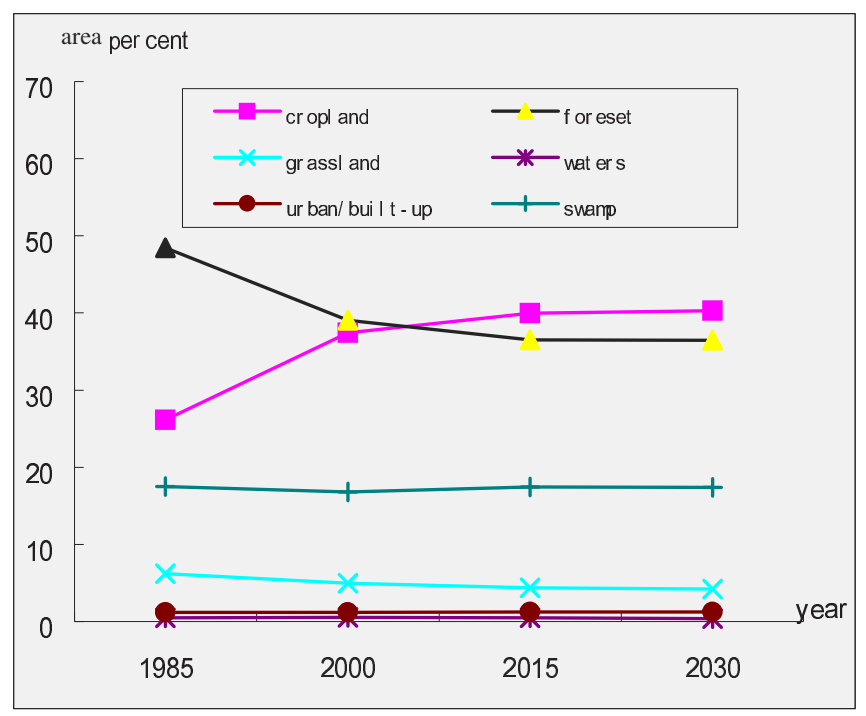

Fig. 10. The land use/cover changes in 1985, 2000, 2015 and 2030 

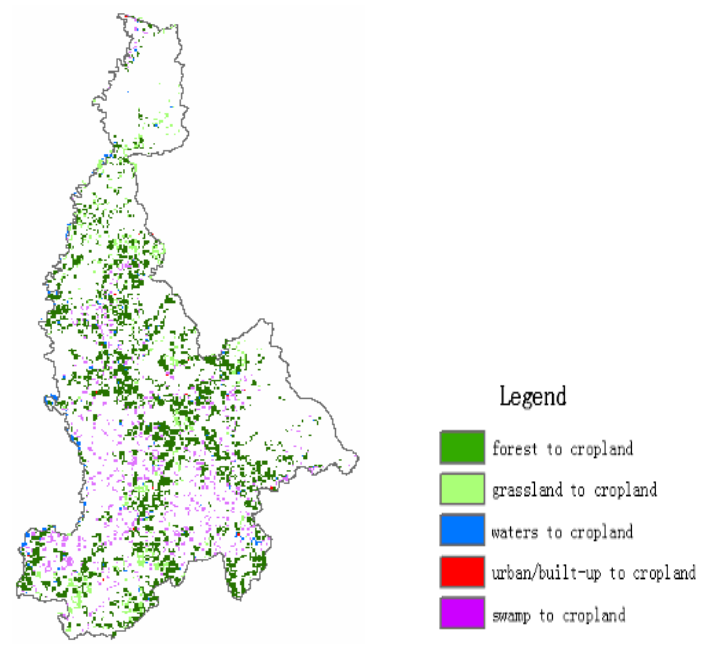

Fig. 11. The predicted increase cropland in 2015

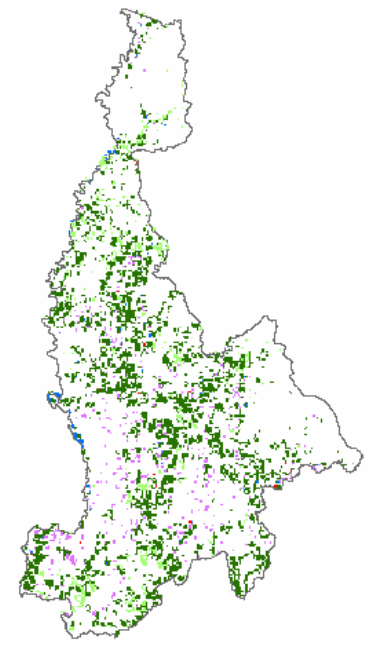

Fig. 12. The predicted increase cropland in 2030

\section{CONCLUSION}

This paper presents the results for analyzing and predicting land use change by using remote sensing data, CA-Markov model. From this study of land use/cover changes in Nenjiang county between 1985 and 2000, some conclusions were obtain: The increase in agricultural areas from 26.12 percent to 37.42 percent is closed related to the increase in population. The population has increased the demand fro food and has led to intensification of the shrink of forest and expansion of cultivated land. The simulation of land uses in the year 2015 and 2030 indicated that the suitable to croplands decreased rapidly after 2000 .

\section{REFERENCES}

Clark Labs, 2006, http://www.clarklabs.org.

Couclelis H. Cellular worlds: A framework for modeling micro-macro dynamics. Environment and Planning A, 1985 (17): 585-596.

Couclelis H. Macrostructure and micro behavior in a metropolitan area. Environment and Planning B, 1989 (16): 151-154.

ESRI, 2006, http: //www.esri.com.

Fenglei Fan \& Yunpeng Wang \& Zhishi, 2007, Wang Temporal and spatial change detecting (1998-2003) and predicting of land use and land cover in Core corridor of Pearl River Delta (China) by using TM and ETM+ images, Environ Monit Assess, DOI 10.1007/s10661-007-9734-y.

Leica Geosystems Geospatial Imaging LLC, 2006, http://www.idasnet.com/idas_site/idasnet_eng/ products/gis_software/ leica_erdas. Htm. 
Michael R. Muller and John Middleton, 1994, A Markov model of land-use change dynamics in the Niagara Region, Ontario, Canada Landscape Ecology vol. 9 no. 2 pp 151-157 (1994).

Tobler WR. A computer movie simulating urban growth in the Detroit region. Economic Geography, 1970 (46): 234-240.

Turner BL, Meyer WB, Skole DL. 1994. Global land use/land cover change: towards an integrated study. Ambio, 23 (1): 91-95.

Von Neumann J, Burks AW. 1966, Theory of self-reproducing automata. Urbana: University of Illinois Press, 35-39.

White R, Engelen G. Cellular automata and fractal urban form: A cellular modeling approach to the evolution of urban land-use patterns. Environment and Planning A, 1993 (25): 1 175-1 199.

YE Baoying, Zhang Y-Z, Zhang S-W, et al. 2003. Effect of land cover change in Neijiang watershed on runoff volume. Bull Soil Water Conser, 23(2):15-18 (in Chinese).

YE Baoying, 2002, The land use/cover change in Nenjiang watershed and its driving forces analysis. Ph.D. Dissertation, Changchun Institute of Geography, CAS (in Chinese). 